\title{
Representações da mídia acerca da violência por arma branca e de fogo
}

\author{
Media representations of violence by firearms and cold weapons
}

\section{Sílvia Furtado de Oliveira1, André Vinícius Batista de Assis², Ardigò Martino³, Letícia Antônio Costa ${ }^{4}$, Rodrigo Guimarães dos Santos Almeida ${ }^{5}$, Ana Paula de Assis Sales ${ }^{6}$}

'Autora para correspondência. Universidade Federal de Mato Grosso do Sul. Campo Grande, Mato Grosso do Sul, Brasil. ORCID: 0000-0001-5706-2577. silviafoliveiraa@gmail.com Escola de Saúde Pública Dr. Jorge David Nasser. Campo Grande, Mato Grosso do Sul, Brasil. ORCID: 0000-0002-7725-3415. andrejornalista1@gmail.com ${ }^{3}$ Instituto Integrado de Saúde, Universidade Federal de Mato Grosso do Sul. Campo Grande, Mato Grosso do Sul, Brasil. ORCID: 0000-0003-0429-7772. ardigo.martino@gmail.com ${ }^{4}$ Universidade Federal de Mato Grosso do Sul. Campo Grande, Mato Grosso do Sul, Brasil. ORCID: 0000-0002-7680-6356. costaleticiaa@hotmail.com 5Universidade Federal de Mato Grosso do Sul. Campo Grande, Mato Grosso do Sul, Brasil. ORCID: 0000-0002-4984-3928. rgclaretiano@gmail.com 6Universidade Federal de Mato Grosso do Sul. Campo Grande, Mato Grosso do Sul, Brasil. ORCID: 0000-0002-1327-5383. anasales.sales@gmail.com

RESUMO | O objetivo do estudo foi identificar o discurso de um veículo de comunicação sobre a violência entre homens por arma branca e de fogo em uma capital da região CentroOeste. Trata-se de uma pesquisa qualitativa, de caráter documental, a qual foi realizada mediante as notícias sobre violência entre homens por arma branca e de fogo veiculadas por um jornal com acesso online. Os dados coletados resultaram em 5 categorias temáticas: Dramatização das notícias; policiais, civis e transgressão; estado paralelo; álcool como potencializador; e vingança e rixa como motivação. Esta pesquisa contribui no sentido de provocar discussões que tangenciam os temas mídia, determinantes sociais e violência, de forma a instigar reflexão e debate sobre a percepção da mídia no âmbito da violência entre homens.

PALAVRAS-CHAVE: Violência. Armas. Meios de comunicação. Desigualdades em saúde.

\begin{abstract}
This work aimed to identify the discourse of a vehicle of communication about the violence between men by cold weapons and firearms in a capital of the Centro-Oeste region. This study is a documentary research of qualitative approach. This research showed discourse of a online newspaper regarding aggressions by cold weapons and firearms whose victims are men. The data collected resulted in 5 thematic categories: Dramatization of news; police, civil and transgression; parallel state; alcohol as a potentiator; and revenge and brawl as motivation. This research provokes discussions about the media, social determinants and violence, in order to instigate reflection and debate about the influence of the media in the scope of violence between men.
\end{abstract}

KEYWORDS: Violence. Weapons. Communications media. Healthcare disparities. 


\section{Introdução}

A violência é um processo sócio-histórico evitável que, apesar de não ser próprio da natureza humana, emerge na vida em sociedade e assume um delineamento específico em cada uma delas. Logo, apesar de não ser um problema próprio do setor saúde, afeta-o diretamente, já que atinge a saúde individual e coletiva, evidencia a inadequação da organização tradicional dos serviços de saúde e indica a necessidade de relações de trabalho integradas e com vistas aos intersetores, além dos custos humanos envolvidos (Minayo, 2007).

Assim, para compreender a violência, é necessário focar nas múltiplas dimensões nas quais ela se apresenta: a violência física propriamente dita, a violência simbólica, a violência cultural e a violência estrutural, com o sofrimento social que a acompanha. Essa abordagem multidisciplinar é útil no sentido de analisar a violência como fato individual e social ao mesmo tempo e compreender como os mesmos sujeitos podem ser, de forma concomitante, vítimas e autores de violência (Minayo, 2007).

A violência física é contemplada na Classificação Internacional de Doenças da Organização Mundial da Saúde pelo nome genérico de causas externas. Esse grupo representa um espaço de destaque no Brasil e é observado uma tendência crescente, sobretudo no que concerne a agressão como causa específica, mesmo sem ter, em território nacional, conflitos armados secundários à guerra, como é observado em outras partes no mundo (Fórum Brasileiro de Segurança Pública [FBSP], 2018).

Igualmente, a violência simbólica e cultural e a violência estrutural agem como fatores determinantes da saúde da população e podem ser facilmente revelados a partir da análise das desigualdades em saúde, considerando que as vítimas de violência em todas as suas formas, sofrem danos à saúde a curto, médio e longo prazo (Minayo, 2007).

No Brasil, a violência foi incluída oficialmente na agenda da saúde em 2001 por intermédio da Política Nacional de Redução da Morbimortalidade por Acidentes e Violência, devido sua proporção epidêmica. Tal documento admite os efeitos deletérios da violência no país, reconhecendo-a como um fenômeno de caráter social, histórico e cultural (Brasil, 2001); porém, as outras dimensões da violência, como o racismo, a violência institucional, a violência estrutural e o sofrimento social têm dificuldade de ser incluídas.

O Brasil ocupa a incômoda posição de quinta nação mais violenta do planeta com uma taxa de 28,6 homicídios por 100 mil habitantes, segundo dados da Organização Mundial de Saúde. Somente em 2016, houveram 62.517 homicídios, ultrapassando, pela primeira vez na história do país, o nível de 30 mil homicídios por 100 mil habitantes (taxa igual a 30,3), o que representa uma taxa 30 vezes maior do que a da Europa. Esse fato revela uma naturalização dessa problemática e a necessidade de formulação de políticas públicas (FBSP, 2018).

Por outro lado, o Brasil também está entre as nações mais desiguais do mundo, ocupando a nona posição no ranking global de desigualdade de renda, além de ser destaque, também, no que concerne às desigualdades raciais e entre sexos (Oxfam Brasil, 2018) e, portanto, trata-se de uma das nações que carrega maior violência institucional e social.

Dessa forma, é possível reconhecer a violência como um fenômeno determinado socialmente ao constatar que os homens jovens, na faixa etária dos 15 aos 29 anos, negros (somatório de pretos e pardos), residentes nos bairros mais pobres da periferia e de baixa escolaridade representam o grupo mais susceptível ao processo de vitimização (Cerqueira \& Coelho, 2017).

Perante a magnitude da violência, tal fenômeno ganhou notoriedade e passou a ser mais um produto da mídia. Ressalta-se, nesse sentido, que mais do que veículo de informação, a mídia atua na legitimação de poder, ao passo que exerce uma grande influência cultural (Njaine \& Minayo, 2002), já que disponibiliza formas de enxergar e entender determinado fato. Portanto, a mídia e a informação se colocam, no bem e no mal, como atores importantes na produção de violência simbólica e cultural.

Nessa perspectiva, observa-se que pelo fato de as notícias serem destituídas de neutralidade, essas possuem o poder, por meio de suas narrativas, de produzir impacto na percepção dos indivíduos acerca dos acontecimentos, bem como fortalecer ideias, estereótipos e preconceitos já instaurados no pensamento coletivo (Ramos \& Novo, 2003). 
É comum que os profissionais de saúde prestem os cuidados às vítimas de violência em serviços de emergência permeados pelo imaginário popular divulgado pelos veículos de comunicação. Esse fato, aproxima as ações do modelo hegemônico do cuidar, centrado nas questões puramente biológicas, sem real imersão no contexto mais amplo que envolve essa problemática: de iniquidades e ausência de estado, resultante de múltiplas formas de violência; percepção essa que deveria ser inerente à formação e, portanto, à prática dos profissionais.

Diante disso, este estudo teve como objetivo identificar o discurso da mídia sobre violência entre homens por armas branca e de fogo em uma capital da Região Centro-Oeste.

\section{Método}

Trata-se de um estudo do tipo documental, retrospectivo, de abordagem qualitativa, o qual foi realizado mediante levantamento de notícias sobre violência por arma branca e de fogo entre homens em Campo Grande, Mato Grosso do Sul (MS).

O estudo foi realizado no banco de dados do website de um jornal impresso veiculado diariamente há 64 anos. A escolha pelo veículo de comunicação sucedeu devido a tradição que o jornal possui em MS, além de se tratar do mais antigo veículo impresso e o de maior circulação no estado.

Foram definidos os seguintes critérios de inclusão: notícias de um jornal envolvendo homens com idade entre 15 e 59 anos, vítimas de violência interpessoal de natureza física por arma branca e/ou de fogo no perímetro urbano de Campo Grande - MS.

O perímetro urbano de Campo Grande - MS é dividido, para fins administrativos, em sete regiões urbanas, que abrangem 77 bairros, são elas: Anhanduizinho, Bandeira, Centro, Imbirussu, Lagoa, Prosa e Segredo.

Foram excluídas as notícias que não permitiam identificar a região urbana de ocorrência da violência, as notícias que fossem uma repercussão de um caso de violência já narrado pelo veículo de comunicação, bem como as notícias que possuíam mulheres como perpetradoras.
Para a coleta de dados, as notícias do jornal foram acessadas no banco de dados de maneira online. Após a leitura das manchetes da seção "cidades", foram lidas na íntegra as notícias que possuíam a violência como tema central e, em seguida, essas foram selecionadas para o estudo conforme os critérios de seleção, resultando em 23 notícias. A amostra do estudo foi composta por notícias publicadas a partir do mês de maio de 2017, o qual foi definido aleatoriamente, e a captação de notícias foi interrompida em novembro, devido a saturação teórica.

Após a seleção, foi utilizado um formulário contendo os seguintes aspectos: (1) relacionados à circunstância de ocorrência: idade da vítima, região urbana de ocorrência, tipo de arma e tipo de confronto; (2) relacionados ao discurso midiático: título e temática vinculada ao discurso, descrição de características sociais, econômicas e culturais, bem como de confrontos entre diferentes grupos e existência de culpabilização ou julgamento da vítima; e (3) outros aspectos que poderiam suscitar discussão.

Para a análise de dados, foram extraídos os núcleos de sentido das narrativas das notícias incluídas no estudo. Os dados das narrativas receberam tratamento à luz da técnica de Análise de Conteúdo por intermédio das seguintes etapas: pré-análise; exploração do material; e tratamento dos resultados, inferência e interpretação (Bardin, 2011).

Dessa forma, a análise dos dados iniciou-se com uma leitura flutuante do material de estudo com o intuito de captar as ideias centrais. Em seguida, na exploração do material, foi realizada a exploração em concomitância com a definição das categorias temáticas, de acordo com o grau de contiguidade. Por fim, no tratamento dos resultados, inferência e interpretação foi realizada a condensação e o destaque das informações, que findaram nas interpretações inferenciais (Bardin, 2011).

Para fins de codificação, os trechos das notícias selecionadas foram identificados por letra e algarismo arábico, como exemplo "T1", sendo que "T" corresponde a trecho e "1" ao número do trecho.

Quanto aos aspectos éticos, por se tratarem de dados de domínio público, não foi necessária a solicitação de autorização de pesquisa ao Comitê de Ética para a realização do estudo. 


\section{Resultados e Discussão}

\section{Caracterização das ocorrências}

Nesse estudo, as 23 notícias veiculadas e selecionadas narraram o óbito ou ferimento de 30 homens. Do total de atos de violência entre homens, 10 (33,33\%) ocorreram na Anhanduizinho, 6 (20\%) na Bandeira, 5 $(16,67 \%)$ na Lagoa, $5(16,67 \%)$ na Imbirussú, 2 (6,67\%) na Segredo e $2(6,67 \%)$ na Prosa, nenhuma matéria veiculada ocorreu na região urbana Centro.

A região Anhanduizinho, onde foram veiculadas mais notícias sobre violência é caracterizada por ser a região da maior exclusão social, já que possui os piores indicadores de desigualdade, pobreza, razão de dependência demográfica, taxa de alfabetização, anos de estudo do chefe da família, indicador de direitos fundamentais suprimidos e participação de jovens. Em contrapartida, a região Centro segue a tendência inversa a essa realidade, sendo considerada a região de menor exclusão (Sauer, Campêlo \& Capille, 2012).

Nesse sentido, confirma-se que a segregação social, imposta em espaços urbanos distantes dos centros das cidades torna-os desprovidos de infraestruturas capazes de propiciar uma sociedade mais justa e igualitária. Sendo assim, o morrer e matar nesses territórios configuram uma interface aceita socialmente; fato que confere a impressão de existência de uma outra cidade dentro da mesma cidade, onde o status estabelecido determina o quanto o viver e morrer são possíveis.

Conforme Oliveira, Costa, Saviczki, Almeida e Sales (2018), além de não ter sido narrado situações de violência na região centro, essas concentraram-se, em maior escala, nos espaços mais distantes dessa região urbana, assumindo uma tendência radial com maior número de ocorrência de atos violentos veiculados pela mídia em regiões de maior exclusão social.

Dessa forma, torna-se notório que há nexo causal entre as diferentes formas de violência e essas tipologias contemplam e fazem parte da cidade como um todo, de forma a moldar os cidadãos à cultura da segregação e da precarização da vida. Porém, o peso da violência física ainda recai de forma mais incisiva sobre os indivíduos que já são submetidos, continuamente, a outras formas de violência, sobretudo a estrutural, institucional e cultural.

Nas notícias veiculadas, as relações entre homens e a violência foram conectadas a outras temáticas. Do total de notícias, em 11 (47,83\%) foi mencionada a interlocução com o roubo ou furto, $8(34,78 \%)$ estavam relacionados à vingança ou rixa, $5(21,74 \%)$ ao consumo de drogas, sejam elas lícitas ou ilícitas; 4 (17,39\%) às facções criminosas e em $3(13,04 \%)$ casos foi evidenciado o narcotráfico. Em algumas matérias houve sobreposição de temáticas (Tabela 1).

Tabela 1. Caracterização das temáticas vinculadas à violência entre homens no discurso da mídia

\begin{tabular}{cll}
\hline Temática* & N & $\%$ \\
\hline Roubo/furto & 11 & 47,83 \\
Confronto ente policiais e civis & 9 & 39,13 \\
Vingança ou rixa & 8 & 34,78 \\
Uso de drogas & 5 & 21,74 \\
Facções criminosas & 4 & 17,39 \\
Narcotráfico & 3 & 13,04 \\
\hline
\end{tabular}

Nota: * Mais de uma temática relacionada. 
A partir dos dados coletados, os discursos foram analisados e localizadas as unidades de registro que continham significado relacionado ao objeto do estudo. Essas unidades foram agrupadas em categorias temáticas, conforme descrito na Análise de Conteúdo. Assim, foram identificadas 5 categorias que convergiam para o objetivo proposto: (1) Dramatização das notícias; (2) policiais, civis e transgressão; (3) estado paralelo; (4) álcool como potencializador; e (5) vingança e rixa como motivação.

\section{Dramatização das notícias}

A análise das matérias veiculadas permitiu identificar que, ao invés de problematizar a questão da violência urbana, imergir em suas causas e instigar a reflexão dos leitores, a mídia tende a dramatizar as notícias relacionadas à violência, como ilustram os seguintes discursos:

"A vítima morreu em frente a uma ótica, e quando ainda estava ferido e ensanguentado, disse quem tinha dado as facadas nele" (T13).

"Jovem, 22 anos, foi assassinado por um adolescente de 17 anos enquanto assistia filme com amigos em uma casa. Baleado na clavícula direita, ele caminhou até a varanda do imóvel, onde morreu antes mesmo que pudesse ser socorrido" (T17).

'Bom menino' [subtítulo da matéria]. Na delegacia, a mãe, inconsolável, lembra do filho que acabara de perder precocemente" (T19).

Em um estudo sobre as representações da mídia impressa em situações de violência, constatou-se que, nas matérias sobre violência, a mídia transcende a comunicação dos fatos e, assim, tende a espetacularização e dramatização das notícias (Ramos \& Novo, 2003).

Essa realidade não se restringe ao Brasil: em estudo realizado com um meio de comunicação chileno também foi observada a utilização de hipérbole na veiculação de matérias jornalísticas (Obando, 2015). Rocha (2016) alerta que isso acontece porque o compromisso da mídia prova não ser com a informação e nem com o jornalismo, mas com o capital e, nesse âmbito, o importante é apreender a atenção de quem consome notícias, sendo essa a real mercadoria das empresas de comunicação.
Essa dramatização promove, em muitos casos, a espetacularização do fato noticiado e, assim, a sociedade passa a entender as mortes violentas com certa banalidade ou como se fossem resultados inerentes, por exemplo, a quem está em condição de conflito com a lei. Assim, limita o entendimento do leitor acerca das situações de violência, que passa a enxergá-la de maneira desconexa dos fatores que originam esse agravo, ao invés de entendê-la como um processo multifacetado que repercute em todos os segmentos da sociedade.

\section{Policiais, civis e transgressão}

Esse estudo permitiu identificar que os confrontos entre policiais e civis são uma realidade no contexto de violência instaurado na capital. Nesse âmbito, observa-se nas entrelinhas dos discursos que, além da violência de natureza física, há também o componente estrutural e institucional envolvido, que coloca policiais e civis como autores e vítimas de violência em diferentes momentos, conforme explicitado a seguir:

"Assaltante foi morto em confronto com a Polícia Militar. Um comparsa dele teria conseguido fugir. Os dois teriam roubado uma caminhonete. A caminhonete foi abandonada e os dois homens invadiram uma casa para despistar os militares, que foram recebidos a balas. Houve reação e o homem foi morto com um tiro"

"Dois jovens, 18 e 20 anos, roubaram em uma lanchonete, na noite de quinta-feira, em Campo Grande. O policial deu voz de prisão aos assaltantes, que começaram a disparar. Durante a troca de tiros, um dos bandidos foi baleado na perna e ficou caído no chão, enquanto o comparsa conseguiu fugir" (T3).

"Jovem, 19, foi morto pela Polícia Militar durante troca de tiros no Jardim Santa Felicidade, depois de roubar um veículo Land. Ele estaria com um revólver calibre 32" (T12).

Em nenhuma das notícias houve vitimização de policiais nas situações de confronto. Em 2015, do total policiais mortos, $74,58 \%$ morreram fora de serviço. Porém, mesmo no ambiente de trabalho, a mortalidade policial ainda é considerada alta se contrastada à realidade de outros países (Fórum Brasileiro de Segurança Pública [FBSP], 2016). 
Nos EUA, em sete anos (2005-2012), o sistema de notificação mais abrangente analisado em um estudo aponta que houveram 1.552 mortes resultantes de força policial (Barber et al., 2016). Por outro lado, no Brasil, apenas no ano de 2015, houveram 3.320 mortes decorrentes de intervenções policiais. Com uma taxa de letalidade de 1,6 por 100 mil habitantes e cerca de 9 pessoas mortas por dia, a polícia brasileira é a mais mata do mundo (FBSP, 2016; Souza \& Minayo, 2017).

Nesse estudo, comprovou-se a transformação de vidas humanas em corpos descartáveis no discurso da mídia. Nas entrelinhas das matérias observou-se que o homicídio passa a ser justificado quando a vítima possui antecedentes criminais, conforme ilustram os discursos T2 e T6.

"Ficha: morto em posto tinha passagens na polícia. (...) Homem, 38, tinha registro de roubo desde 1997, estava foragido e era apontado como líder de uma quadrilha"

\section{“(...) Homem foi executado com tiros na cabeça e o corpo estava em terreno baldio. Segundo a polícia, a vítima tinha várias passagens por crimes como lesão corporal e dano ao patrimônio" (T6).}

Obando (2015) encontrou realidade semelhante em um estudo realizado no Chile sobre o tratamento noticioso direcionado aos indivíduos em conflito com a lei. Nesse estudo, o autor comprovou, por meio de análise qualitativa, que a mídia enfatiza o passado de transgressão de normas nas notícias sobre violência, além de apresentar discurso homogeneizante, estereotipado e condenatório ao retratarem esses indivíduos em uma posição de perigo para a sociedade.

Nesse âmbito, ressalta-se que a cobertura insistente de maneira sensacionalista e sem imersão nas reais origens da violência pode influenciar a opinião dos indivíduos e, associada a um discurso de desvalorização da vida, seja de forma velada ou declarada, de homens de determinados segmentos da sociedade, reforça estigmas e contribui para a passividade social diante da retroalimentação do ciclo da violência. Logo, a própria mídia atua como produtora de violência cultural nesse contexto.

Em outros trechos, foi possível verificar que os atos perpetrados pela polícia não são considerados como violência pelo veículo de comunicação. Nas manchetes das notícias envolvendo civis, essas encontram-se acompanhadas da palavra "violência" ou aparecem de forma a sintetizar a ocorrência, já nos casos em que envolvem a PM, as manchetes vêm acompanhadas da palavra "reação" ou "revide", como verificado nos trechos a seguir:

"Reação: suspeito de assalto é morto pela polícia" [manchete] (T5).

"Reação: homem morto por policial em assalto" [manchete] (T15).

"Revide: PM já matou 21 suspeitos de crimes em confrontos" [manchete] (T8).

Essa realidade também foi encontrada no estudo de Ramos e Novo (2003) ao verificarem que, quando um indivíduo em conflito com a lei é assassinado por policias, a mídia impressa tende a tratar como um caso de legítima defesa, mesmo quando trata-se, na verdade, de homicídio. Nesse processo, a mídia tende a evidenciar a ação policial violenta como um sinal de eficiência e, por conseguinte, uma postura positiva a ser adotada diante dos casos de situações de pessoas em conflito com a lei.

Ao explorar, em T8, o fato dos agentes da lei terem efetuado 21 mortes em situações de confronto, a mídia coloca em evidência e reforça duas concepções: a primeira salienta o poder de legitimar a pena capital ao infrator, sem o direito de defesa e julgamento pelo sistema judiciário; e a segunda legitima o uso excessivo da força policial, desde que direcionada contra aqueles que destoam da ideia de cidadãos de bem presente no imaginário social.

Assim, observa-se que o discurso da mídia atribui a violência, única e exclusivamente, às pessoas em conflito com a lei. Porém, é possível evidenciar que policiais e civis, em seus diferentes papeis sociais, alternam-se entre produtores e produto de violência e não há paradoxo nessa relação. Dessa forma, é possível demonstrar que esses indivíduos que se encontram em conflito com a lei também são vítimas e, assim, desmistificar a crença de são naturalmente violentos e o elo principal da violência instaurada.

Contrapondo essa visão, Piveta e Carvalhaes (2017), enfatizam que esse discurso condenatório e estigmatizado não se restringe aos indivíduos em atos de ilicitude; mas envolvem viés classicista contra todo aquele que se assemelha, de acordo com o consciente 
coletivo, à imagem de delinquência, ou seja, os indivíduos residentes nas regiões mais periféricas da cidade e pertencentes a estrato socioeconômico desprivilegiado. Logo, há uma diferenciação, por classe social, na linguagem utilizada na veiculação de notícias e, até mesmo, no alcance dessas. Assim, a própria mídia participa da produção de violência estrutural e simbólica, por intermédio da violência cultural, ao reforçar padrões e estigmas.

Além disso, constatou-se que as notícias veiculadas pela mídia deram ênfase no possível uso de drogas ilícitas por parte das vítimas de violência, conforme verificado nos discursos abaixo:

"Homem de 34 anos foi agredido com facada na barriga. Aos policiais, testemunha contou que o homem é dependente químico, mas não soube informar o que pode ter motivado o crime. A Polícia Civil investiga o caso" (T23).

"Homem, 35, foi encontrado morto por volta das 7 h de ontem. De acordo com a polícia, a suspeita é de que ele seria usuário de drogas e que o crime tenha ocorrido em razão de acerto de contas" (T7).

Essa exaltação acerca do consumo de drogas em matérias jornalísticas também foi encontrada em um estudo realizado por meio de análise de notícias de um jornal de circulação estadual sobre o perfil dos homens autores de violência. Nesse estudo, os autores verificaram que, quando os indivíduos fazem uso de drogas ilícitas, esse fato é evidenciado de maneira estigmatizada pela mídia. Nessa perspectiva, ressaltam ainda que essa tendência de taxar os indivíduos como "usuários de drogas" é observada, sobretudo, ao discursar sobre homens de camadas menos favorecidas economicamente (Santos et al., 2014).

É factual, ainda, justificar a morte de indivíduos de determinados segmentos da sociedade pelo consumo de drogas ilícitas. Entretanto, o uso de drogas ilícitas não se restringe a espaços urbanos socialmente fragilizados, ou seja, essa realidade está presente nas diferentes esferas sociais. Porém, nas descrições da mídia, o homem morto, em situação de drogadição e pertencente aos espaços urbanos onde imperam as fragilidades sociais, é culpabilizado pelas situações de violência que sofreu e a este não é dada a possibilidade de receber um tratamento adequado para esse problema de saúde complexo.

\section{Estado paralelo}

Foi possível observar que, para a mídia, existe um estado paralelo que, em contraste com os três poderes do estado de direito, formula suas próprias normas, julga e executa. Esse estado representa o crime organizado ou facções criminosas, como é denominada pelo veículo de comunicação. Nas descrições das situações de violência é possível constatar um cenário de guerra entre o Primeiro Comando da Capital e o Comando Vermelho, que têm protagonizado confrontos recorrentes, conforme verifica-se nos trechos a seguir:

"Jovem, 22, foi baleado e, enquanto recebia atendimento, disse que havia sido mantido em cativeiro no local, para ser executado pela facção PCC, uma vez que foi acusado de pertencer ao rival CV" (T9).

"Jovem, 22 anos, foi esquartejado depois de supostamente desrespeitar o PCC. O corpo dele foi encontrado em pedaços. Toda a ação foi filmada e compartilhada nas redes sociais pela organização criminosa, como forma de demonstração de poder e intimidação de seus outros integrantes" (T14).

"A guerra entre faç̧ões fez mais uma vítima em Campo Grande. Jovem de 18 anos, supostamente integrante do $C V$, foi sequestrado por cinco criminosos ligados ao PCC e levado para ser morto. Porém, mesmo depois de baleado no ombro, peito e pescoço e esfaqueado na barriga e nas costas, ele conseguiu escapar e pedir ajuda" (T20).

"A guerra entre facções pelo controle do tráfico de armas e drogas avançou da fronteira com o Paraguai para a Capital Sul-Mato-Grossense ganhou um novo episódio violento após vários atentados e execuções cruéis. Na noite de quinta-feira, homem, 35 anos, foi atingido por três tiros" (T21)

O crime organizado possui uma dinâmica própria de funcionamento e disputa pelo controle do mercado de drogas ilícitas. De acordo com Rios (2013), a violência gerada pela ação dos diferentes grupos ligados ao crime organizado pelo controle do tráfico de drogas no México acontece em decorrência de dois fatores: (1) pelo surgimento de batalhas por território; e (2) pelas operações de aplicação de leis pela polícia. Infere-se, portanto, que no contexto da capital, a chamada guerra às drogas e a competitividade por domínio do território para a comercialização de drogas ilícitas estejam atreladas às constantes situações de violência relatadas pela mídia. 
É preciso enfatizar, nesse contexto, que apesar de as violências criminais e interpessoais serem mais visíveis nos trechos analisados nessa categoria temática, essas são apenas partes de um fenômeno mais complexo e menos visível; mas que impõe condições injustas e, da mesma forma, provoca prejuízos à coletividade, que é a violência institucional envolvida na problemática do crime organizado. Nesse âmbito, o sentido de vida toma outro rumo e vidas se perdem sem, muitas vezes, serem percebidas (FBSP, 2018), exceto pela exposição da mídia do gran finale.

\section{Álcool como potencializador}

A análise do material coletado permitiu identificar a constante interlocução entre a ocorrência de situações de violência e o uso de bebidas alcoólicas. Ambientes onde comercializam-se esses produtos também aparecem no discurso da mídia como palco da ocorrência de violência, como verifica-se nos seguintes discursos:

"Está internado homem, 49 anos, esfaqueado na noite de segunda-feira. Ele foi atacado pelo cunhado, 49, durante bebedeira" (T24).

“O primeiro boletim de ocorrência aponta que o homem [perpetrador] estava embriagado e o rapaz [vítima] teria furado a fila do banheiro. Quem estava [com a vítima] também relata a embriaguez [do perpetrador]" (T18).

$\mathrm{Na}$ análise documental sobre os danos à terceiros relacionado ao consumo de álcool, a qual utilizou sete jornais com circulação em todo o Reino Unido e três na Escócia, os autores constataram que a mídia impressa veicula frequentemente notícias que vinculam o consumo excessivo de álcool à violência, denominando-o como um flagelo da sociedade e um risco à coesão social. Além disso, a mídia impressa relata que o álcool não apenas estimula as pessoas a cometerem crimes, mas também torna as pessoas mais vulneráveis a se tornarem vítimas (Wood et al., 2014).

Ressalta-se, porém, que ao contrário do Reino Unido; onde, por meio do estudo supracitado, a mídia mostrou-se preponderante no auxílio para a formulações de políticas públicas para o controle do consumo de álcool, no Brasil, a tendência mostra-se inversa; já que, conforme Conceição, Silva, Araújo, Santana e Santos (2012), há um incentivo, por parte da mídia, ao consumo de bebidas alcoólicas.
Em geral, as propagandas reforçam o uso do álcool pela sua exposição insistente e de maneira atrativa e, nesse processo, eximem-se da necessidade de retratar a realidade dos agravos a saúde. É fato que o consumo de álcool, mesmo que eventual, expõe os indivíduos a situações de risco, dentre as quais, a violência. Nesse cenário, a permissividade e até estímulo por parte da mídia e da sociedade ao consumo de bebidas alcoólicas, associados à omissão do poder público, contribuem para a ocorrência da violência

\section{Vingança e rixa como motivação}

Esse estudo constatou a recorrente veiculação de violência entre homens motivadas por vingança ou rixa. Assim, no âmbito da violência como consequência de atos provocados por vingança entre membros do núcleo familiar, ressalta-se que, apesar das crianças, idosos e mulheres serem as maiores vítimas de violência intrafamiliar (Machado et al., 2014), esse tipo de violência também foi narrado pela mídia tendo homens jovens e adultos como autores e vítimas.

A análise das matérias veiculadas permitiu identificar contextos familiares conturbados, em que espaços residenciais de membros do núcleo familiar aparecem como palco do cenário de violência, como ilustra o seguinte discurso T22.

"Homem, 53 anos, foi morto a facadas e o suspeito é o próprio irmão. Ele já teria avisado a sobrinha que mataria o pai dela. A vítima levou ao menos três facadas na região do tórax. Além de ameaçar o próprio irmão, ele também teria afirmado que mataria o sobrinho, filho da vítima" (T22).

A violência intrafamiliar é definida pelo desequilíbrio de poder exteriorizada nas relações familiares, que geram intolerância, abuso ou opressão (Minayo, 2007). Em um estudo qualitativo sobre a violência intrafamiliar sob a óptica de quem a vivencia, constatou-se que esse tipo de violência emerge de contextos familiares habitualmente conflituosos e marcados pela agressão física, além de ofensas, rejeição, humilhação e carência de afeto. Essa realidade, apesar repercutir na saúde física, mental e social dos indivíduos, é difícil de ser percebida pelas vítimas dessa forma de violência (Magalhães et al., 2017).

Nas notícias veiculadas pela mídia foi possível constatar, ainda, que os indivíduos tendem a usar a força física para vingar outro ato violento, revelando uma 
dupla violência intrafamiliar. Em ambos os casos, sobressaiu-se as relações desiguais de poder entre homens e mulheres que, ainda hoje, torna as mulheres vítimas de violência de gênero. Assim, em T11 e T16 constata-se a violência de gênero como motivação para a violência entre homens com função parental.

"Rapaz, 23 anos, é suspeito de matar com dez facadas o padrasto, 39 anos, para defender a mãe das agressões.

Depois de brigar com a esposa e tentar agredi-la, o homem [padrasto] entrou em luta, tentando feri-lo com uma facada e um martelo. O rapaz [enteado] conseguiu desarmá-lo e o golpeou dez vezes" (T11).

"A polícia está à procura de homem, 43 anos, suspeito da morte do enteado. O crime aconteceu na madrugada de ontem, depois que o rapaz [vítima] teria tentado agredir a mãe, ao exigir dinheiro dela para comprar drogas. Ele levou um tiro no peito" (T16).

Nesse âmbito, o estudo de Borges e Alencar (2006) realizado com indivíduos do sexo masculino em regime de liberdade condicional pelo crime de homicídio doloso vai de encontro a essa realidade ao constatar que a segunda principal motivação para os indivíduos cometerem homicídio é a defesa da própria vida ou de familiares.

Além disso, a análise do material de estudo possibilitou, ainda, verificar que o sentimento de vingança transcende os espaços familiares e também se faz presente fora do ambiente domiciliar. Porém, destaca-se que não se tratam de pessoas desconhecidas, mas de indivíduos que em algum momento se conheceram e as circunstâncias os levaram a alimentar o desejo de vingança, como transcrito abaixo:

"Jovem, 20, foi assassinado a tiros de revolver, na tarde de ontem. Informações iniciais dão conta de que o crime teria sido em consequência de uma briga ocorrida no último sábado, em um bar"(T1).

"Dois homens mortos a tiros. Os primeiros indícios são de que o crime tenha sido praticado por vingança"

(T10).

De acordo com Dirk e Moura (2017), os motivos fúteis, no qual os autores incluíram a rixa e a vingança, representam a terceira maior causa de violência contra a pessoa, ficando atrás do tráfico de drogas e das intervenções policiais. Para Dalbosco (2006), a vingança pessoal representa uma alternativa às pessoas para a resolução de conflitos quando o sistema judiciário não cumpre com o papel socialmente esperado, isto é, a sensação de impunidade faz com que emerja o desejo de fazer a própria justiça.

Ademais, os espaços são passíveis da ocorrência de violência, sobretudo onde as demandas sociais não satisfazem necessidades e limites pessoais e de papéis não conseguem ser estabelecidos ao processo de vida. Os espaços e papéis sociais precisam e devem permitir a perspectiva do crescimento coletivo e da cultura da paz, já que ambientes onde essas necessidades não são atendidas preponderam, impactam e aumentam os casos de violência.

\section{Considerações finais}

Os resultados desse estudo possibilitaram, por intermédio da análise do conteúdo, a compreensão acerca da percepção de um jornal na pauta da violência entre homens. Assim, foi possível refletir e analisar a maneira maniqueísta com que o veículo de comunicação impresso trata a questão da violência entre homens, de forma a ditar quem merece ser ouvido e quem está resignado ao silêncio, julgamento e culpabilização.

A violência interpessoal de natureza física, pelo potencial de produzir incapacidades e risco de morte imediata, é mais visível nos discursos da mídia e, nesse processo, formas mais sutis de violência permanecem veladas, negligenciadas, naturalizadas ou são, até mesmo, legitimadas, sobretudo quando praticadas por pessoas e instituições detentoras de poder; porém, essas não são menos concretas que a violência física e possuem o mesmo potencial de causar danos e sofrimento.

Em nenhuma das matérias do estudo foi discutida ou citada a violência como um problema para o setor saúde, o que demonstra que a visão arcaica, punitiva e reducionista da violência em seu componente físico e como uma demanda exclusiva do setor judiciário ainda não foi superada. Esse fato deixa evidente a falta de discernimento da dimensão do fenômeno, bem como do seu impacto para a saúde dos indivíduos, família e coletividade.

Por último, é preciso enfatizar a necessidade de restaurar o aspecto ético que envolve a veiculação de 
notícias sobre violência por parte da mídia, sobretudo por essa ser corresponsável por promover, juntamente com outros segmentos da sociedade, melhoria nas condições de vida da coletividade. Assim, os veículos de comunicação necessitam trazer a público novas concepções acerca do fenômeno da violência, de maneira a provocar no leitor uma interpretação menos estereotipada e superficial sobre essa problemática social.

\section{Agradecimentos}

Este artigo é resultado de pesquisa aprovada para apresentação no $7^{\circ}$ Congresso Ibero-Americano em Investigação Qualitativa - CIAIQ, realizado de 10 a 13 de julho de 2018 em Fortaleza, Ceará, Brasil.

\section{Contribuições dos autores}

Oliveira, S. F. participou da concepção, coleta de dados, interpretação dos resultados, delineamento, análise e interpretação dos resultados, redação do artigo científico e encaminhamento do artigo científico. Assis, A. V. B. participou da interpretação dos dados e revisão crítica do conteúdo do artigo científico. Martino, A. participou da interpretação dos dados e redação do artigo científico. Costa, L. A. participou da interpretação dos dados e redação do artigo científico. Almeida, R. G. S. participou da interpretação dos dados e revisão crítica do conteúdo do artigo científico. Sales, A. P. A. participou da concepção, interpretação dos resultados, delineamento, análise e interpretação dos resultados e redação do artigo científico.

\section{Conflitos de interesses}

Nenhum conflito financeiro, legal ou político envolvendo terceiros (governo, empresas e fundações privadas, etc.) foi declarado para nenhum aspecto do trabalho submetido (incluindo mas não limitando-se a subvenções e financiamentos, participação em conselho consultivo, desenho de estudo, preparação de manuscrito, análise estatística, etc.).

\section{Referências}

Barber, C., Azrael, D., Cohen, A., Miler, M., Thymes, D., Wang, D. E., ...Hemenway, D. (2016). Homicides by police: comparing counts from the national violent death reporting system, vital statistics, and supplementary homicide reports. American Journal of Public Health, 106(5), 922-927. Recuperado de https://ajph.aphapublications. org/doi/10.2105/AJPH.2016.303074. doi: $10.2105 /$ AJPH.2016.303074
Bardin, L. (2011). Análise de conteúdo (4ª ed). Lisboa: Edições 70: Persona.

Borges, L. S., \& Alencar, H. M. (2006). Moralidade e homicídio: um estudo sobre a motivação do transgressor. Psicologia: Reflexão e Crítica, 19(3), 451-459. Recuperado de http:// www.scielo.br/pdf/prc/v19n3/a14v19n3.pdf. doi: $10.1590 /$ S0102-79722006000300014

Brasil. Ministério da Saúde. (2001). Política Nacional de Redução da Morbimortalidade por Acidentes e Violências. Brasília: Ministério da Saúde. Recuperado de http://bvsms.saude. gov.br/bvs/publicacoes/acidentes.pdf

Cerqueira, D., \& Coelho, D. S. C. (2017). Democracia Racial e homicídio de jovens negros na cidade partida. Rio de Janeiro: IPEA. Recuperado de http://www.ipea.gov.br/portal/ images/stories/PDFs/TDs/td_2267.pdf

Conceição, V. M., Silva, S. E. D., Araújo, J. S., Santana, M. E., \& Santos, L. M. S. (2012). O processo das representações sociais na mídia impressa: a bebida alcoólica, o alcoolismo e o leitor em foco. Tempus Actas de Saúde Pública, 6(3), 201 215. Recuperado de http://tempusactas.unb.br/index.php/ tempus/article/view/1164/1063. doi: 10.18569/tempus. v6i3.1164

Dalbosco, C. (2006). Ressonâncias da morte violenta de adolescentes e jovens: estudo teórico clínico de famílias em sofrimento (Dissertação de mestrado). Instituto de Psicologia, Universidade de Brasília, Brasília, DF, Brasil. Recuperado de http://repositorio.unb.br/handle/10482/3609

Dirk, R., Moura, L. (2017). As motivações nos casos de letalidade violenta da região metropolitana do Rio de Janeiro. Cadernos de Segurança Pública, 9(8), 1-11. Recuperado de http://www.isprevista.rj.gov.br/download/Rev20170802.pdf

Fórum Brasileiro de Segurança Pública. (2016). Anuário brasileiro de segurança pública 2016. São Paulo: Fórum Brasileiro de Segurança Pública. Recuperado de https:// documentos.mpsc.mp.br/portal/manager/resourcesDB. aspx?path $=2229$

Fórum Brasileiro de Segurança Pública. (2018). Anuário brasileiro de segurança pública 2018. São Paulo: Fórum Brasileiro de Segurança Pública. Recuperado de http://www. forumseguranca.org.br/wp-content/uploads/2019/02/ Anuario-2019-v6-infogr\%C3\%A1 fico-atualizado.pdf

Machado, J. C., Rodrigues, V. P., Vilela, A. B. A, Simões, A.V., Morais, R. L. G. L, \& Rocha, E. N. (2014). Violência intrafamiliar e as estratégias de atuação da equipe de Saúde da Família. Saúde e Sociedade, 23(3), 828-840. Recuperado de http://www.scielo.br/pdf/sausoc/v23n3/01041290-sausoc-23-3-0828.pdf. doi: 10.1590/5010412902014000300008 
Magalhães, J. R. F., Gomes, N. P., Mota, R. S., Campos, L. M., Camargo, C. L, \& Andrade, S. R. (2017). Violência intrafamiliar: vivências e percepções de adolescentes. Escola Anna Nery, 21(1), e20170003. Recuperado de http://www.scielo.br/pdf/ean/v21n1/1414-8145-ean-2101-e20170003.pdf. doi: 10.5935/1414-8145.20170003

Minayo, M. C. S. (2007). Conceitos, teorias e tipologias de violência: a violência faz mal à saúde individual e coletiva. In K. Njaine, S. G. Assis, \& P. Constantino (Orgs.), Impactos da Violência na Saúde (pp. 21-42). Rio de Janeiro: Editora FIOCRUZ.

Njaine, K., \& Minayo, M. C. S. (2002). Análise do discurso da imprensa sobre rebeliões de jovens infratores em regime de privação de liberdade. Ciência \& Saúde Coletiva, 7(2), 285-297. Recuperado de http://www.scielo.br/pdf/csc/ v7n2/10248.pdf. doi: 10.1590/S1413-81232002000200009

Obando, E. S. (2015). Impacto de los medios de comunicación de masas sobre la opinión pública: ¿sobre los peligros de la adolescencia?. Diversitas Perspectivas em Psicologia, 11(1), 37-49. Recuperado de http://www.scielo.org.co/ pdf/dpp/v11n1/v11n1a03.pdf. doi: 10.15332/s17949998.2015.0001.02

Oliveira, S. F., Costa, L. A., Saviczki, P. L., Almeida, R. G. S., \& Sales, A. P. A. (2018, julho). Espaços urbanos e violência à luz dos Determinantes Sociais da Saúde. Anais do Congresso IberoAmericano de Investigação Qualitativa - CIAIQ. Fortaleza, CE, Brasil, 7. Recuperado de https://proceedings.ciaiq.org/ index.php/ciaiq2018/article/view/1887/1837

Oxfam Brasil (2018). País estagnado: um retrato das desigualdades brasileiras. São Paulo: Oxfam Brasil. Recuperado de https://www.oxfam.org.br/sites/default/files/arquivos/ relatorio_desigualdade_2018_pais_estagnado_digital.pdf

Piveta, R. T. A., \& Carvalhaes, F. F. (2017). A Juventude das periferias como alvo da violência: uma análise sobre enunciados difundidos pela sociedade brasileira. Revista Psicologia Política, 17(39), 277-292. Recuperado de http://pepsic.bvsalud.org/scielo.php?script=sci_ arttext\&pid=S1519-549X2017000200007\&lng=pt\&tlng=pt

Ramos, F. P., \& Novo, H. A. (2003). Mídia, violência e alteridade: um estudo de caso. Estudos de Psicologia, 8(3), 491497. Recuperado de http://www.scielo.br/pdf/epsic/ v8n3/19971.pdf. doi: 10.1590/S1413-294X2003000300016

Rios, V. (2013). Why did Mexico become so violent? A selfreinforcing violent equilibrium caused by competition and enforcement. Trends in Organized Crime, 16(2), 138-155. Recuperado de https://link.springer.com/ article/10.1007\%2Fs12117-012-9175-z. doi: $\underline{10.1007 /}$ s12117-012-9175-z
Rocha, R. L. (2016). Os negócios da mídia e a comunicação da saúde. Cadernos de Saúde Pública, 32(2), e00000616. Epub. Recuperado de http://www.scielo.br/pdf/csp/v32n2/0102311x-csp-0102-311x00000616.pdf. doi: 10.1590/0102$311 \times 00000616$

Santos, A. C. B., Lima, V. L. A., Sampaio, D. L., Silva, A. F., Sena, L. X., \& Gomes, V. R. (2014). Violência por parceiro íntimo: a versão da mídia impressa e as contribuições para a enfermagem. Revista Baiana de Enfermagem, 28(1), 50-60. Recuperado de https://portalseer.ufba.br/index.php/ enfermagem/article/view/8341/8706. doi: 10.18471/rbe. $\underline{\mathrm{v} 28 \mathrm{i} 1.8341}$

Sauer, L., Campêlo, E., \& Capillé, M. A. L. (2012). O mapeamento dos índices de inclusão e exclusão social em Campo Grande-MS: uma nova reflexão. Campo Grande: Editora Oeste. Recuperado de http://www.campogrande. ms.gov.br/sas/downloads/mapeamento-dos-indices-deinclusa\%CC\%83o-e-exclusa\%CC\%83o-social-em-campogrande-ms/

Souza, E. R, \& Minayo, M. C. S. (2017). Segurança pública num país violento. Cadernos de Saúde Pública, 33(3), e00036217. Recuperado de http://www.scielo.br/pdf/csp/v33n3/16784464-csp-33-03-e00036217.pdf. doi: 10.1590/0102$311 \times 00036217$

Wood, K., Patterson, C., Katikireddi, S. V., \& Hilton, S. (2014). Harms to "others" from alcohol consumption in the minimum unit pricing policy debate: a qualitative content analysis of UK newspapers (2005-12). Addiction, 109(4), 578-584. Recuperado de https://onlinelibrary.wiley.com/ doi/epdf/10.1111/add.12427. doi: 10.1111/add.12427 